\title{
The impact of potassium citrate therapy in the natural course of Medullary Sponge Kidney with associated nephrolithiasis
}

\author{
Elisa Cicerello, Matteo Ciaccia, Giandavide Cova, Mario Mangano \\ Urology Unit, Department of Surgery, Ospedale Ca' Foncello, Treviso, Italy.
}

\begin{abstract}
Summary Objectives: The present study was carried out to evaluate the effectiveness of medical therapy with potassium citrate in preventing calculosis complicating Medullary Sponge Kidney (MSK) without renal acidification defects.

Materials and methods: In a open, uncontrolled, retrospective analysis, 49 MSK patients with nephrolithiasis without renal tubular acidosis, underwent a complete metabolic evaluation and received potassium citrate therapy 4-6 g/day. The course of stone disease before and after citrate therapy was determined in each patient from a combination of clinical history, past records, radiographs and kidney ultrasound. The rate of new stone formation/pt/yr, of endourological and extracorporeal procedures, of urinary tract infection (UTI) and number of hospitalization before and after medical treatment were calculated.

Results: Metabolic anomalies (hypercalciuria, hypocitraturia, hyperuricuria and hyperoxaluria) were present in $83 \%$ of the patients. Follow-up before and after alkali citrate therapy was comparable (4.7+/-1.4 and 4.9+/-1.7 years respectively).

Medical treatment significantly reduced rates of stone formation from $2.0+/-1.0$ to $0.2+/-0.5 \mathrm{pt} / \mathrm{yr}$, ureteroscopy (URS) from $0.9+/ 0.8$ to $0.4+/-0.5 \mathrm{pt} / \mathrm{yr}$, extratracoporeal lithotripsy (ESWL) from 1.1+/-0.8 to 0.4+/-0.6 pt/yr, urinary tract infections (UTIs) from $0.8+/-1.2$ to $0.3+/-0.5 \mathrm{pt} / \mathrm{yr}$ and hospitalization from 1.1+/-0.6 to 0.2+/-0.3 pt/yr, $p<0.001$. This effect was observed also in MSK patients without metabolic anomalies. In 35 patients the asymptomatic disappearance of calcium stones was also observed.

Conclusions: Our study documents the effectiveness of potassium citrate therapy in preventing neprolithiasis in MSK patients also in the absence of distal tubular acidosis. It suggests that in MSK patients alkali citrate may promote calcium stone dissolution by oral administration.
\end{abstract}

KEY WORDS: Medullary Sponge Kidney (MSK); Nephrolithiasis; Potassium citrate therapy.

Submitted 6 March 2018; Accepted 6 December 2018

\section{INTRODUCTION}

Medullary Sponge Kidney (MSK) is a congenital abnormality of the renal medulla characterized by the presence of multiple small cysts. These changes were described by the Italian radiologist Leonarduzzi and a decade later Cacchi e Ricci confirmed these finding histopatologically (1). The condition is diagnosed on excretory urograms according to radiographic criteria that include the characteristic "paint brush" appearance of the dilated tubules draining into flattened calyces (2) which may favour salts crystallization and precipitation with consequently stone formation.

Nephrolithiasis in MSK causes pain and urinary infection and requires radiological and ultrasound exams and urological treatments for stone removal.

Medical treatment to prevent nephrolithiasis has been known from 30 years and numerous studies suggest the effectiveness of potassium citrate in preventing stone formation in different form of nephrolithiasis with economic advantages $(3,4)$.

Previous works have demonstrated in MSK a variety of metabolic abnormalities which, together the papillary collecting duct dilatation, could play a role in stone formation, including hypercalciuria, hypocitraturia, hyperuricuria and urinary acidification defects (5-7). Also the concurrence of hyperparathyroidism and MSK has been reported which suggest that renal hypercalciuria from disordered nephron function may lead to parathyroid hyperplasia and adenoma (8).

In the past medical treatment with potassium citrate was performed only in the presence of acidification defects and hypocitraturia was shown to normalize with concorrent reduction in stone formation (9).

The present study was carried out to evaluate the effectiveness of medical therapy with potassium citrate in preventing calculosis complicating MSK in the absence of acidification defects.

\section{Patients And methods}

From January 1994 to June 2013 in the Urologic clinic of the Treviso General Hospital we evaluated 842 patients with recurrent calcium stones. Sixty-one (7.2\%) had the characteristic features of MSK on intravenous pyelograms (2), i.e. radial distribution of calcification around enlarged papillae, flattened calyces and dilated collecting tubules with or without cystic deformities. In 58 patients the defect was bilateral and in all cases tubular ectasia involved three or more papillae. For this study, all radiographs were reviewed by one of us and at least one radiologist unaware of the previous diagnosis and diagnostic conclusion was confirmed in $100 \%$ of the cases. 
Starting from 2000, our standard medical treatment for all MSK stone formers was potassium citrate (4 to $6 \mathrm{gm}$. per day orally in 2-3 doses). For the aim of this study, we have retrospectively evaluated patients with at least 2 years of continuos potassium citrate therapy and in whom distal renal tubular acidosis (RTA) had been excluded. Complete RTA is diagnosed when at least 2 of the following conditions are observed: morning urinary $\mathrm{pH}$ higher than 5.5 (in sterile urine), systemic acidemia, urinary citrate excretion lower $100 \mathrm{mg} / 24 \mathrm{~h}$. When only one of the three above is observed, an oral ammonium chloride test (NH4CL load $0.05 \mathrm{~g} / \mathrm{kg} /$ body weight over 3 days) was performed and a fasting urine $\mathrm{pH}$ after test higher than 5.6 coincident with systemic acidemia was considered diagnostic of RTA. As a whole 49 patients (31 males and 18 females, mean age $37.7+/-16.3$ and $30.7+/-$ 15.2 yrs. respectively) with adequate follow-up and compliance to medical treatment form the bases of this report; all patients had defect and the fully developed form of the anatomic features.

Patients had been evaluated before the beginning of potassium citrate therapy with a clinical and metabolic protocol, radiological and ultrasound examinations. Three 24-hour urine samples were collected on an outpatient basis, while eating the usual diet. Urine was analyzed for levels of oxalate, uric acid, calcium, citrate, creatinine, sodium and potassium. After at least 10 hours fasting, venous blood samples were drawn for calcium, phosphate, uric acid, creatinine, and morning spot urine was collected. Idiopathic hypercalciuria was defined as $24 \mathrm{hr}$ urine calcium excretion greater than $300 \mathrm{mg}$, normocalcemia and exclusion of other hypercalciuric conditions. Hyperuricuria was definited as a $24 \mathrm{hr}$ uric acid excretion above $800 \mathrm{mg}$, hypocitraturia as less than 350 $\mathrm{mg}$ and hyperoxaluria as more than $40 \mathrm{mg}$.
Mean follow-up before and after treatment was 4.7+/-1.4 and $4.9+/-1.7$ yrs. respectivelly. The course of stone disease before and after medical treatment was determined in each patient from clinical history, past records, radiographs (KUB xRay, pielography) and kidney ultrasounds: namely, the number of passed stones, of not expulsed stones, of urological procedures (intracorporeal or extracorporeal treatments), of urinary tract infections (UTIs) was registered. UTI episodes were defined as episode of chills, fever and flank pain that led to medical care.

These patients were monitored during potassium citrate theraphy every 6 months with blood creatinine, sodium and potassium and urine analysis. The compliance to medical treatment was evaluated by urinary $\mathrm{pH}$ since potassium citrate alkalinizes the urine. Ultrasound was carried out every 6 months and KUB X-ray with tomography once year to ascertain the exact number of stones. CT scan was only performed in few cases and was excluded for the aim of this study.

A new stone was defined as the radiographic apperance, removal, or passage of a stone not present on a prior radiograph. Passed or removed stone were analyzed whenever possible.

The rate of new stone formation/year, of endourological and extracorporeal procedures, of UTI and number of hospitalization before and after medical treatment were calculated as means +/- SD of values from each patient. The statistical analysis was carried out by the Student ttest for paired data.

\section{RESULTS}

Hypercalciuria was present in 21 (43\%) patients, hypocitraturia in $23(47 \%)$, hyperuricuria in $14(28 \%)$ and hyperoxaluria in 8 (16\%). Thirteen patients were hyper-

Table 1.

Effect of potassium citrate therapy on complications in MSK patients with index episodes.

\begin{tabular}{|lcccccc|}
\hline & $\begin{array}{c}\text { Pre-treatment } \\
\text { (all patients) }\end{array}$ & $\begin{array}{c}\text { Post-treatment } \\
\text { (all patients) }\end{array}$ & $\begin{array}{c}\text { p value } \\
\text { (Student t-paired test) }\end{array}$ & $\begin{array}{c}\text { Pre-treatment } \\
\text { (patients without } \\
\text { metabolic anomalies) }\end{array}$ & $\begin{array}{c}\text { Post-treatment } \\
\text { (patients without } \\
\text { metabolic anomalies) }\end{array}$ & $\begin{array}{c}\text { p value } \\
\text { (Student t-paired test) }\end{array}$ \\
\hline Stones/pt/yr & $2.0 \pm 1.0$ & $0.2 \pm 0.5$ & $<0.001$ & $1.6 \pm 1.0$ & $0.03 \pm 0.07$ & $<0.005$ \\
\hline $\mathrm{URS} / \mathrm{pt} / \mathrm{yr}$ & $0.9 \pm 0.8$ & $0.4 \pm 0.5$ & $<0.001$ & $0.9 \pm 0.6$ & $0.2 \pm 0.4$ & $<0.05$ \\
\hline $\mathrm{ESWL} / \mathrm{pt} / \mathrm{yr}$ & $1.1 \pm 0.8$ & $0.4 \pm 0.6$ & $<0.001$ & $1.1 \pm 0.9$ & $0.2 \pm 0.3$ & $<0.05$ \\
\hline $\mathrm{UTI} / \mathrm{pt} / \mathrm{yr}$ & $0.8 \pm 1.2$ & $0.3 \pm 0.5$ & $<0.001$ & $0.8 \pm 07$ & $0.2 \pm 0.3$ & $<0.01$ \\
\hline Hospitalization/pt/yr & $1.1 \pm 0.6$ & $0.2 \pm 0.3$ & $<0.001$ & $1.1 \pm 0.9$ & $0.2 \pm 0.3$ & $<0.01$ \\
\hline
\end{tabular}

Table 2.

Effect of potassium citrate therapy on complications in MSK patients without index episodes.

\begin{tabular}{|lcccccc|}
\hline & $\begin{array}{c}\text { Pre-treatment } \\
\text { (all patients) }\end{array}$ & $\begin{array}{c}\text { Post-treatment } \\
\text { (all patients) }\end{array}$ & $\begin{array}{c}\text { p value } \\
\text { (Student t-paired test) }\end{array}$ & $\begin{array}{c}\text { Pre-treatment } \\
\text { (patients without } \\
\text { metabolic anomalies) }\end{array}$ & $\begin{array}{c}\text { Post-treatment } \\
\text { (patients without } \\
\text { metabolic anomalies) }\end{array}$ & $\begin{array}{c}\text { p value } \\
\text { (Student t-paired test) }\end{array}$ \\
\hline Stones/pt/yr & $1.9 \pm 1.0$ & $0.2 \pm 0.5$ & $<0.001$ & $1.5 \pm 0.9$ & $0.03 \pm 0.07$ & $<0.005$ \\
\hline $\mathrm{URS} / \mathrm{pt} / \mathrm{yr}$ & $0.9 \pm 0.7$ & $0.4 \pm 0.5$ & $<0.001$ & $0.9 \pm 0.6$ & $0.2 \pm 0.4$ & $<0.05$ \\
\hline $\mathrm{ESWL} / \mathrm{pt} / \mathrm{yr}$ & $1.1 \pm 0.7$ & $0.4 \pm 0.6$ & $<0.001$ & $1.0 \pm 0.8$ & $0.2 \pm 0.3$ & $<0.05$ \\
\hline $\mathrm{UTT} / \mathrm{pt} / \mathrm{yr}$ & $0.8 \pm 1.1$ & $0.3 \pm 0.5$ & $<0.001$ & $0.8 \pm 07$ & $0.2 \pm 0.3$ & $<0.01$ \\
\hline Hospitalization/pt/yr & $1.0 \pm 0.6$ & $0.2 \pm 0.3$ & $<0.001$ & $1.0 \pm 0.9$ & $0.2 \pm 0.4$ & $<0.01$ \\
\hline
\end{tabular}


calciuric and hypocitraturic, 4 hyperuricuric and hypercalciuric and 5 hyperuricuric, hypercalciuric and hypocitraturic). In 9 patients (17\%) no metabolic anomaly was found. No patient with MSK was hypercalcemic and none had hyperparathyroidism.

The chemical analysis of stone removed or passed was calcium oxalate $(\mathrm{CaOx})$ and /or calcium phosphate $(\mathrm{CaP})$ and mixed ( $\mathrm{CaOx}$ plus uric acid) in 5 patients.

Starting from the first control after beginning potassium citrate therapy urinary $\mathrm{pH}$ significantly increased (from $5.63+/-0.61$ to $6.74+/-0.55$ respectively, $\mathrm{p}<0.0001$ ) without significant changes in plasma creatinine, calcium, phosphate, uric acid, sodium and potassium.

Furthermore medical treatment significantly reduced rates of stone formation from $2.0+/-1.0$ to $0.2+/-0.5$ $\mathrm{pt} / \mathrm{yr}$, ureteroscopy (URS) from $0.9+/ 0.8$ to $0.4+/-0.5$ $\mathrm{pt} / \mathrm{yr}$, extratracoporeal lithotripsy (ESWL) from 1.1+/-0.8 to $0.4+/-0.6 \mathrm{pt} / \mathrm{yr}$, urinary tract infections (UTIs) from $0.8+/-1.2$ to $0.3+/-0.5 \mathrm{pt} / \mathrm{yr}$ and hospitalization from $1.1+/-0.6$ to $0.2+/-0.3 \mathrm{pt} / \mathrm{yr}, \mathrm{p}<0.001$.

This effect was observed also in MSK patients without metabolic abnormalities (Table 1).

To rule out that these results were due to a "regression to the mean" bias, we excluded from the analysis the index episodes bringing patients to our attention.

$\boldsymbol{A}$
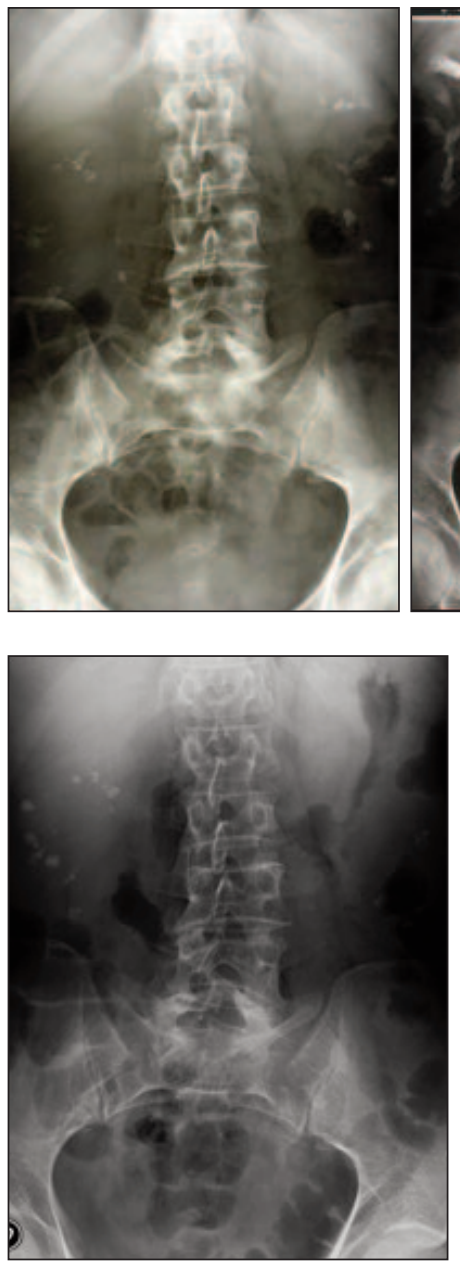

c
A

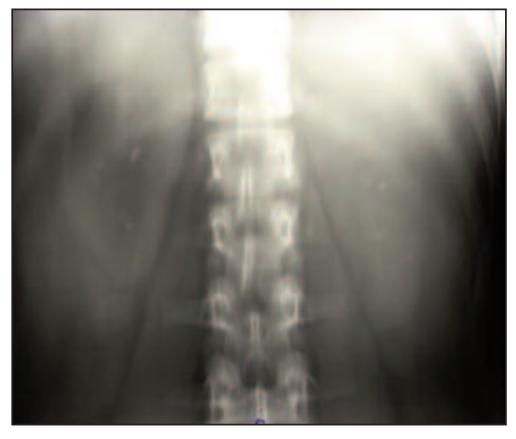

Figure 2.

Man 39 yrs old admitted to our clinic for right flank pain. A, B, X-Ray plus urogram showed bilateral nephrolithiasis, more evident on the right kidney. The patient was given potassium citrate (4 g per day orally in 2 doses).

C, X-Ray 3 yrs later revealed the asymptomatic disappearance of most of the stones. No urological treatment had been performed.
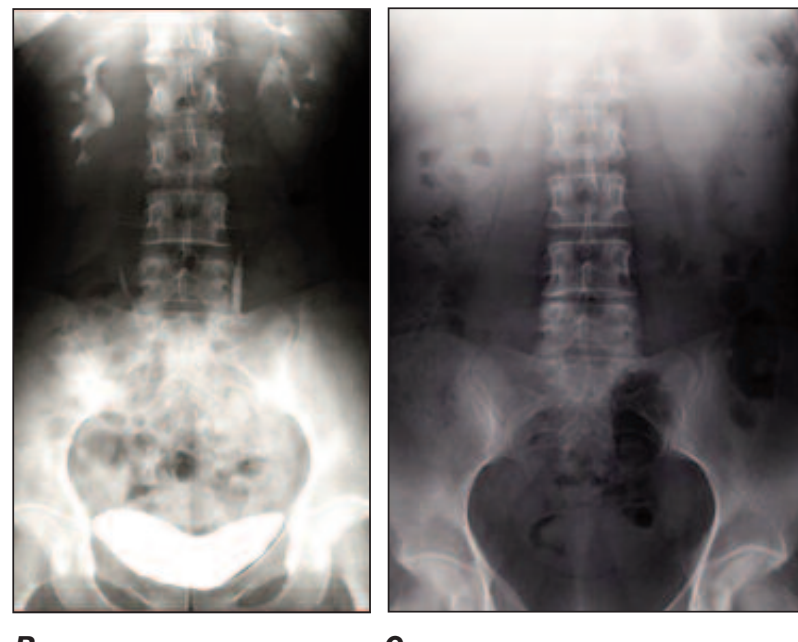

B

c

Table 2 shows the amended results and confirms the favourable activity of alkali citrate treatment.

Furthermore, in 35 patients we have observed the disappearance of stones present on previous x-Ray (Figures 1, 2).

\section{Discussion}

The frequency of radiographic features of MSK may vary from 2.3 to $21 \%$ of patients with calcium stones $(5,8)$. The incidence of MSK in our patients whith recurrent calcium nephrolithiasis was $7.2 \%$; for the aim of this study only those patients with the fully developed form of the anatomic defect, easily recognized on routine intravenous pyelograms, were considered.

Patients with MSK usually come to the attention of physicians because of kidney stones. The frequent occurrence of kidney stones is both dependent on the metabolic and anatomic abnormalities. Anatomical abnormalities, which determine stasis of urine and infection, may account for renal stones in 17\% of our cases lacking metabolic abnormalities. The fact that not all MSK patients have metabolic abnormalities has been already reported $(5,10)$. Therefore, when urinary infection is present, it could be the result rather than the cause of the stones (11).

Our data show a dramatic reduction in the stone rate 
during citrate therapy in MSK patients without RTA and irrespective of the presence of metabolic stone risk factor. As consequence, also a parallel reduction in urological treatment, UTI and hospitalization was observed. Such an effect is neither prejudiced by a "regression to the mean" bias (Table 2) nor by an ascertainment bias of episodes due to the retrospective nature of the study period before the establishment of potassium citrate therapy. Although we cannot rule out some imprecision in counting the number of episodes, particulary the number of stones, we are confident that our conclusion about the clinical actvity of citrate treatment is correct, since the given estimates before the treatment could only be lower than in real ones.

It is well known that renal tubular acidosis is a common cause of calcium neprolithiasis and nephrocalcinosis. This defect is associated with high urinary $\mathrm{pH}$ and low urinary citrate causing the formation of calcium stones. It has also been reported that potassium citrate can correct the acidosis and ameliorate the hypocitraturia preventing calcium nephrolithiasis (9). Citrate is known to reduce the urinary saturation of calcium oxalate by complexing calcium and reducing its ionic concentration; it also inihibits nucleation and crystal growth of calcium, oxalate and phosphate. Citrate treatment increases urinary citrate excretion, urinary $\mathrm{pH}$ and decreases stone formation also in normocitraturic patients (3). Furthermore, it has also been reported that potassium citrate therapy seems to be effective in preventing renal stones in patients with MSK and nephrolithiasis (12). Thus, citrate therapy modifies the urinary milieu leading to condition less prone to stone formation. However, we also unexpectedly observed by $\mathrm{x}$-Ray examination the disappearance of preesisting stones in 35 patients (Figures 1, 2).

In some patients during the citrate therapy follow-up, we observed at first a fragmentation of the stones (similar to the effect of shock wave lithotripsy), thereafter the disappearance of small fragments, and at last of all fragments. The initial disaggregation of stones suggests that citrate may exert some dissolving effect on the concretions occurring in MSK. While the effect of citrate therapy on dissolution of uric acid is known from a long time, the effect of citrate therapy on dissolution of calcium stones is astonishing. However, in a previosus study Pak too observed a similar finding, i.e., the dissolution of calcium stones after citrate therapy in 8 patients (13).

It is generally assumed that calcium stones cannot be dissolved by systemic therapy. Only the local irrigation with different solution, some containing also potassium citrate, is considered to be capable to dissolve calcium stones (14). In this case, the high citrate concentration, the high levels of calcium complexing molecules such as EDTA and high fluxes used most likely explain the efficacy of local irrigation. It is difficult to speculate on the mechanism explaining the dissolving effect of potassium citrate after oral administration. Of course, one has to admit that citrate may enter into the stone, destroyng the binding between calcium and oxalate or phosphate and fragmenting the stone in chippings that later are asymptomatically eliminated with the urine. However, the urinary levels of citrate after oral assumption are much lower than those constituing the irrigation solution and certainly do not have the same strong calcium chelating power. This migh be congruent with the slower dissolution of the stones in our MSK patients. Furthemore, also the fact that stones in MSK, because of the anatomical abnormalities of precaliceal collecting tubules, are immobilized longer than in non-MSK stones, might play a role. In fact, a longer immobilization should allow a more intense and prolonged effect of even relatively low concentrations of citrate, so that these might be effective. Since the occurrence of mixed calcium and urate stones in MSK is not unsual (in our case population was observed in $9 \%$ of patients), the alternative hypothesis that citrate therapy dissolve the urate component of stones and in such way disaggregated stone may also be advanced.

We have previously reported that citrate therapy improves the clearance of residual stone fragments after ESWL and hypothesized that the action may due to the inhibition of growth and aggregation of calcium salts. According to present results we could advance that citrate therapy promotes the dissolution of calcium stones, like for uric and cistinuric stones. If urinary infection is present, adeguate antibiotic therapy could prevent the growth of infection stones, also reported in our previous study (15).

MSK rarely causes renal failure, but if not treated it could worse the quality of life. However, further studies are necessary to investigate this last issue.

\section{REFERENCES}

1. Gambaro G, Feltrin GP, Lupo A, et al. Medullary Sponge Kidney (Leonarduzzi-Cacchi-Ricci disease): a Padua medical school discovery in the 1930s. Kidney Int 2006; 69:663-670.

2. Cameron S. Medullary sponge kidney. In: Oxford Textbook of Clincal Nephrology, 3rd edn, edited by Davidson AM, Cameron JS, Grunfeld J-P, Ponticelli C, Ritz E, Winearls CG, van Ypersele C. Oxford, Oxford University Press, 2004; pp 2495-2501.

3. Pak CYC. Citrate and renal calculi: An update. Min Electrolyte Metab. 1994; 20:371-377.

4. M SC Morgan, Pearle MS. Medical management of renal stones. BMJ. 2016; 352:i52.

5. O' Neill M, Breslau NA, Pak CYC. Metabolic evaluation of nephrolithiasis in patients with medullary sponge kidney. JAMA 1981; 12:1233-1236.

6. Yagisawa T, Kobayashi C, Hayashi T, et al. Contributory metabolic factors in the development of nephrolitiasis in patients with medullary sponge kidney. Am J Kidney Dis. 2001; 37:1140-1143.

7. Osther PJ, Mathiasen H, Hansen AB, Nissen HM. Urinary acidification and urinary excretion of calcium and citrate in women with medullary sponge kidney. Urol Int. 1994; 52:126-130.

8. Maschio G, Tessitore N, D'Angelo A, et al. Medullary Sponge Kidney and hyperparathyroidism-a puzzling association. Am J Nephrol. 1982; 2:77-84.

9. Preminger GM, Sakhaee K, Skurla C, Pak CYC. Prevention of recurrent calcium stone formation with potassium citrate therapy in patients with distal tubular acidosis. J Urol. 1985; 134: 20-23. 
10. Yendt ER, Cohanim M. Renal calculi. Proc 8th Int Cong. Nephrol 1975, Karger Basel, p 1175.

11. Parks J, Coe F, Strauss A. Calcium nephrolithiasis and medullary sponge kidney. N Engl J Med. 1982; 306:1088-191.

12. Fabris A, Lupo A, Bernich P, et al. Long-term treatment with potassium citrate and renal stones in Medullary Sponge Kidney. CJASN. 2010; 5:1663-1668.

13. Pak CYC, Skhaee K, Fuller CJ. Physiological and physiochemical correction and prevention of calcium stone formation by potassium citrate therapy. Trans Ass Amer Phys. 1983; 96:294-305.

14. Nakatsuka S, Kinoshita H, Ueda H, et al. Combined treatment of Medullary Sponge Kidney by EDTA potassium citrate and extracorporeal shock wave lithotripsy. Eur Urol. 1988; 14:339-342.

15. Cicerello E, Merlo F, Gambaro G, et al. Effect of alkaline citrate therapy on clearance of residual renal stone fragments after extracorporeal shock wave lithotripsy in sterile calcium and infection nephrolitiasis patients. J Urol. 1994; 151:5-9.

\section{Correspondence}

Elisa Cicerello, MD (Corresponding Author)

elisa.cicerello@tin.it

Matteo Ciaccia, MD

matteo.ciaccia@aulss2.veneto.it

Giandavide Cova, MD

giandavide.cova@aulss2.veneto.it

Mario Mangano, MD

mario.mangano@aulss2.veneto.it

Urology Unit, Department of Surgery, Ospedale Ca' Foncello, Treviso, Italy 